\title{
Seismic imaging of sandbox experiments - laboratory hardware setup and first reflection seismic sections
}

\author{
C. M. Krawczyk ${ }^{1, *}$, M.-L. Buddensiek ${ }^{2, *}$, O. Oncken ${ }^{3}$, and N. Kukowski ${ }^{4, *}$ \\ ${ }^{1}$ Leibniz Institute for Applied Geophysics (LIAG), Stilleweg 2, 30655 Hannover, Germany \\ ${ }^{2}$ SINTEF Petroleum Research, S.P.Andersens Veg 15, 7031 Trondheim, Norway \\ ${ }^{3}$ Helmholtz Centre Potsdam, GFZ German Research Centre for Geosciences, Telegrafenberg, 14473 Potsdam, Germany \\ ${ }^{4}$ Friedrich Schiller University, Institute for Geosciences, Burgweg 11, 07749 Jena, Germany \\ * formerly at: Helmholtz Centre Potsdam, GFZ German Research Centre for Geosciences, Germany
}

Correspondence to: C. M. Krawczyk (lotte@liag-hannover.de)

Received: 2 August 2012 - Published in Solid Earth Discuss.: 10 October 2012

Revised: 22 January 2013 - Accepted: 23 January 2013 - Published: 15 February 2013

\begin{abstract}
With the study and technical development introduced here, we combine analogue sandbox simulation techniques with seismic physical modelling of sandbox models. For that purpose, we designed and developed a new miniseismic facility for laboratory use, comprising a seismic tank, a PC-driven control unit, a positioning system, and piezoelectric transducers used here for the first time in an array mode. To assess the possibilities and limits of seismic imaging of small-scale structures in sandbox models, different geometry setups were tested in the first 2-D experiments that also tested the proper functioning of the device and studied the seismo-elastic properties of the granular media used. Simple two-layer models of different materials and layer thicknesses as well as a more complex model comprising channels and shear zones were tested using different acquisition geometries and signal properties. We suggest using well sorted and well rounded grains with little surface roughness (glass beads). Source receiver-offsets less than $14 \mathrm{~cm}$ for imaging structures as small as $2.0-1.5 \mathrm{~mm}$ size have proven feasible. This is the best compromise between wide beam and high energy output, and is applicable with a consistent waveform. Resolution of the interfaces of layers of granular materials depends on the interface preparation rather than on the material itself. Flat grading of interfaces and powder coverage yields the clearest interface reflections. Finally, sandbox seismic sections provide images of high quality showing constant thickness layers as well as predefined channel structures and indications of the fault traces from shear zones. Since these were artificially intro-
\end{abstract}

duced in our test models, they can be regarded as zones of disturbance rather than tectonic shear zones characterized by decompaction. The multiple-offset surveying introduced here, improves the quality with respect to $\mathrm{S} / \mathrm{N}$ ratio and source signature even more; the maximum depth penetration in glass-bead layers thereby amounts to $5 \mathrm{~cm}$. Thus, the presented mini-seismic device is already able to resolve structures within simple models of saturated porous media, so that multiple-offset seismic imaging of shallow sandbox models, that are structurally evolving, is generally feasible.

\section{Introduction}

There is a growing need to measure active processes acting in the Earth's crust and their influence on the surface for both pure and applied research. Additionally, the rapidly evolving geodetic, geophysical and geological observation techniques increase the challenge to integrate all those techniques. Thus, to account for this development, seismic imaging and monitoring techniques have to be integrated, notably involving surface observations, e.g. from satellites, in order to understand active deformation of structures relevant in the crust. This problem has not been fully or systematically approached, since material and logistic expenses are high with respect to field experiments.

In the laboratory, less expensive tools like analogue sandbox simulation have been applied to study geological processes (e.g. Davis et al., 1983; Storti et al., 2000; Lohrmann 
et al., 2003; Gartrell et al., 2005; Hoth et al., 2007, 2008; Boutelier and Oncken, 2011). Sandbox experiments offer unique insights into geodynamic processes, as they allow direct observation of processes, e.g. orogenic wedge evolution, fault activity, or lithospheric scale deformation, which are taking place at inaccessible depths and times (cf. also review of Graveleau et al., 2012). Most of the analogue materials representing upper crustal rocks and sediments, like the widely used quartz sand, corundum sand, mortar, or sugar, are opaque. Thus, direct observation of deformation is only possible at the surface of 3-D models or through bordering glass planes of 2-D models. Although recently new monitoring techniques like X-ray computer tomography (Coletta et al., 1991; Schreurs et al., 2003), particle image velocimetry (PIV, e.g. Baldassarre et al., 2001; Wolf et al., 2003; Hampel et al., 2004; Adam et al., 2005; Rosenau et al., 2009; Reiter et al., 2011), or laser scanning (e.g. Persson et al., 2004; Graveleau and Dominguez, 2008) have led to significant improvements in analysing and transfering sandbox experiments, the challenge to monitor 3-D evolution of structures within opaque bodies remains. To overcome this deficiency, we suggest seismic imaging of sandbox models can provide a promising tool.

Sherlock (1999) and Sherlock and Evans (2001) showed that seismic imaging of structures in granular models is feasible. Because their seismic modelling of granular material is based on zero-offset data, the experiments suffered from high attenuation and especially scattering. Bodet et al. (2010) implemented a monitoring tool based on laser-Doppler vibrometry to systematically characterise granular material in analogue models. They analyzed P-wave first arrival times and surface-wave dispersion regarding the velocity structure. Their results correlate well with dispersion relations for acoustic waves of Jacob et al. (2008) who used a mechanical source for the experiment. However, these attempts do not provide structural images but were restricted to providing good estimates of elastic material properties. This can be, in part, overcome by the laser interferometry setup provided by Bretaudeau et al. (2011) who additionally applied finite element viscoelastic modelling to confirm arrival times and amplitudes of experiments in thermoplastic and resin-based models.

We chose to develop an experimental observation system based on the reflection seismic technique, and specifically the use of an array of receivers and the application of reflection processing to minimize noise (Krawczyk et al., 2007; Buddensiek, 2009). Since the small dilation between sand grains generated by shearing causes reflections, geologic models containing 2 to 3 layers of different densities and a few shearing structures are suitable for imaging. The requirements and sequential aims of such an experimental study encompass (1) a systematic approach to test the material properties and the effects of wave propagation in isotropic and anisotropic media by physical studies (see Buddensiek et al., 2009); (2) various 2-D imaging and processing techniques to

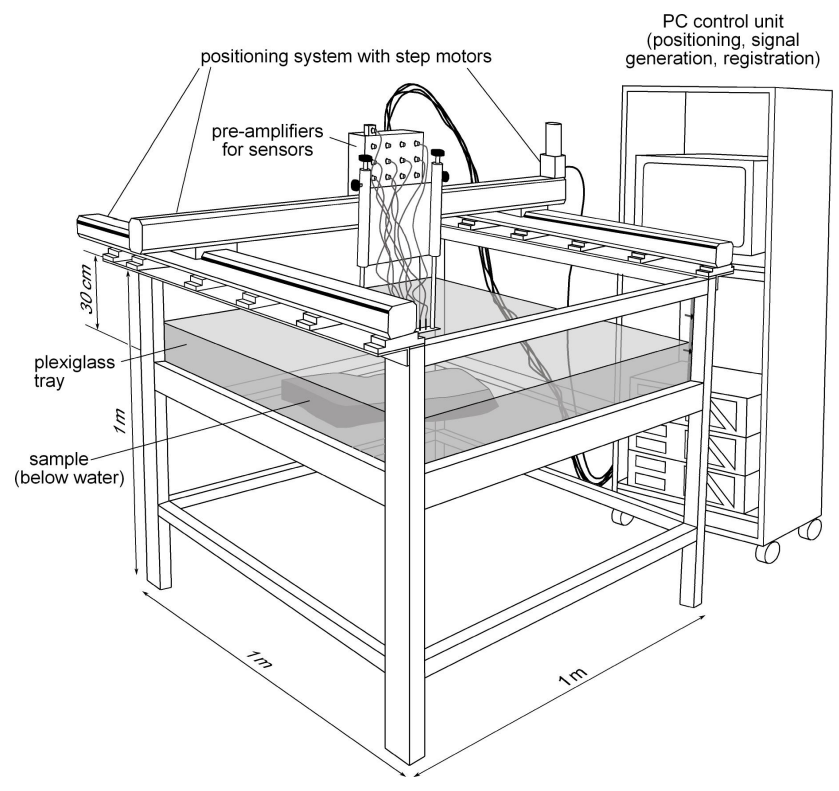

Fig. 1. Experimental device and setup of the mini-seismic system in the laboratory. The system consists of a seismic tank, a PC-driven control unit, a positioning system, and piezoelectric transducers (for technical details see also Table 1 and Figs. 2 and 3).

be tested first on static models, in order to reproduce scaled active seismic experiments (this study); and, finally, (3) timelapse imaging of deforming 3-D structural models.

The main advantage of the application of a mini-seismic system is its non-invasiveness as opposed to the conventional method of slicing the analogue sandbox model, so that timelapse monitoring can be applied. Even though X-ray computerized tomography (CT) analysis also allows the visualization of the interior of an analogue model without destroying it (Colletta et al., 1991; Schreurs et al., 2003), it still requires the analysis of distinct scenes of an evolving model sequence (see Holland et al., 2011). Here, we introduce the new laboratory facility and its technical specifications, and also discuss the tested geometry and material variations based on the first data generation produced by multiple-offset surveying.

\section{Experimental setup and equipment development}

The characteristics of the four major components of the miniseismic system - seismic tank, control unit, positioning system, transducers - are summarised below. Technical specifications are given in Table 1, while Figs. 1 to 3 illustrate the new device and its components.

The requirements and use of technical components as well as the imaging requisites refer also to scaling factors defined by analogue experiments. Here, we consider the setup tested by Lohrmann et al. (2003) followed by Adam et al. (2005) who used granular material that obeys Mohr-Coulomb rheology and scales to nature through its mechanical properties, 
Table 1. Components and technical specifications of the laboratory seismic device.

\begin{tabular}{|c|c|c|}
\hline Component & Partition & Technical specification \\
\hline Seismic tank & $\begin{array}{l}\text { aluminium table with } \\
\text { plexiglass tray }\end{array}$ & size $1 \mathrm{~m} \times 1 \mathrm{~m} \times 0.4 \mathrm{~m}$ \\
\hline \multirow[t]{4}{*}{ PC control unit } & $\begin{array}{l}\text { signal generator } \\
\text { (PCI-board, type MI6030) }\end{array}$ & $\begin{array}{l}\text { max. output } 125 \mathrm{MHz} \text { ( } 14 \mathrm{bit}) \text {; max. } 8 \text { Msamples; } \\
\text { max. output amplitude } 3 \mathrm{~V}\end{array}$ \\
\hline & $\begin{array}{l}\text { signal amplifier } \\
\text { (AC voltage signal amplifier) }\end{array}$ & $\begin{array}{l}\text { input }-2 \text { to }+2 \mathrm{~V} \text {; input resistor } 200 \mathrm{Ohm} \text {; } \\
\text { output }-141 \text { to }+141 \mathrm{~V} \text {; output resistance } 2 \mathrm{k} \mathrm{Ohm} \text {; } \\
\text { bandwidth } 20-500 \mathrm{kHz} \\
(-3 \mathrm{~dB}), 20-1000 \mathrm{kHz}(-6 \mathrm{~dB})\end{array}$ \\
\hline & $\begin{array}{l}\text { preamplifier } \\
\text { (type VV30) }\end{array}$ & $\begin{array}{l}30 \mathrm{~dB} \text { voltage amplification and impedance tuning; } \\
\text { frequency range } 1 \mathrm{kHz}-2 \mathrm{MHz} \text {; max. output amplitude } 3 \mathrm{~V}\end{array}$ \\
\hline & $\begin{array}{l}\text { transient recorder } \\
\text { (three 4-channel PCI-boards, } \\
\text { type MI4022) }\end{array}$ & $\begin{array}{l}\text { for each channel signal amplifier and AD converter; } \\
\text { max. sampling } 20 \mathrm{MHz} \text { (14 bit); max. memory } \\
2 \text { Msamples/channel }\end{array}$ \\
\hline Positioning system & step motors & max. traverse path $1000 \mathrm{~mm}$; accuracy $0.12 \mathrm{~mm} /$ motor step \\
\hline Transducer & $\begin{array}{l}\text { piezoelectric converters } \\
\text { (leadmethaniobate) }\end{array}$ & $\begin{array}{l}\text { max. sensitivity } 425 \mathrm{kHz} \text {; size } 5 \mathrm{~mm} \text { diameter, } 2 \mathrm{~mm} \\
\text { height; coated by a brass cylinder }\end{array}$ \\
\hline
\end{tabular}

i.e. friction and cohesion. Thereby, typical crustal materials and kinematic domains are simulated properly. Since $1 \mathrm{~cm}$ in the model scales to $1 \mathrm{~km}$ in nature, we want to test acquisition geometries in the lab on a tectonic scale first. Thus, our geometry simulates tectonic settings of up to $14 \mathrm{~km}$ horizontal distance, where fault segments of a 150-200 m width are present. This translates to $140 \mathrm{~mm}$ offset and mm-width of structures to be investigated by the mini-seismic device.

\subsection{The seismic tank}

The largest component of the laboratory seismic device is a plexiglass tank of $1 \mathrm{~m} \times 1 \mathrm{~m} \times 0.4 \mathrm{~m}$ dimension (Fig. 1), in which the experiments are conducted. The plexiglass tank is filled with layers of saturated sand resembling geological structures in question on a cm-scale following the needs of physically and geometrically correct scaling (e.g. Hubbert, 1937; Krantz, 1991; Lohrmann et al., 2003). For good coupling, the tank is filled with water after the model has been sieved in and saturated. Saturation time of three to four days was found to be well suited. The sample should be positioned in the centre of the tank to avoid strong side effects during data acquisition.

\subsection{PC system with control unit}

An industry PC (type IPC-9401) contains the signal generator including a signal amplifier and a transient recorder with preamplifier. The PC also drives the step motors for the positioning of the source and receivers (Fig. 2).

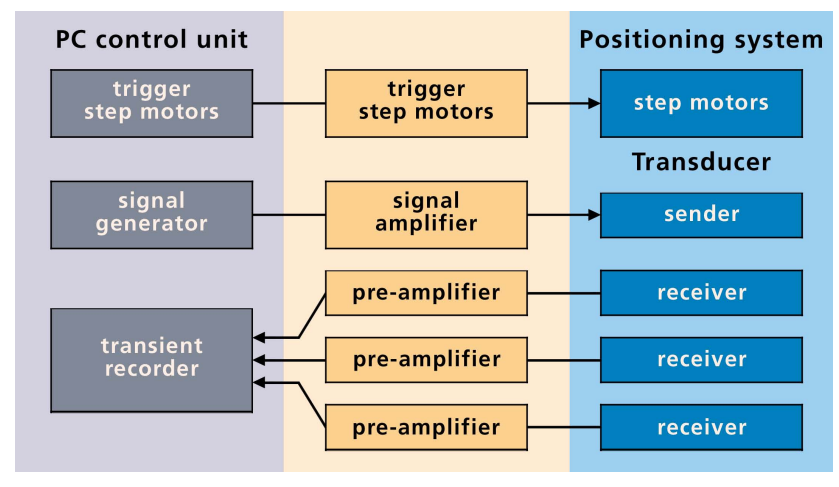

Fig. 2. Schematic illustration of the functions performed by the PC control unit for communication with the positioning system and the transducers.

The technical parameters of the signal generator allow a broad bandwidth and frequency range of the emitted signals that can be recorded in different dynamic ranges (Table 1). Depending on the experiment, different waveforms are available for emission as source signal. This may either be a step function or could consist of 1-10 periods with frequencies between 0.5 to $1 \mathrm{MHz}$, including also additional tapering by sine and cosine envelopes of variable order. For recording of reflected signals, the transient recorder contains three boards with four channels each (Table 1). Thereby, the number of transducers in our laboratory seismic facility is limited to twelve. The channels can be actuated individually, with a memory of 2 Msamples/channel and maximum sampling of $20 \mathrm{MHz}$ (14 bit). 

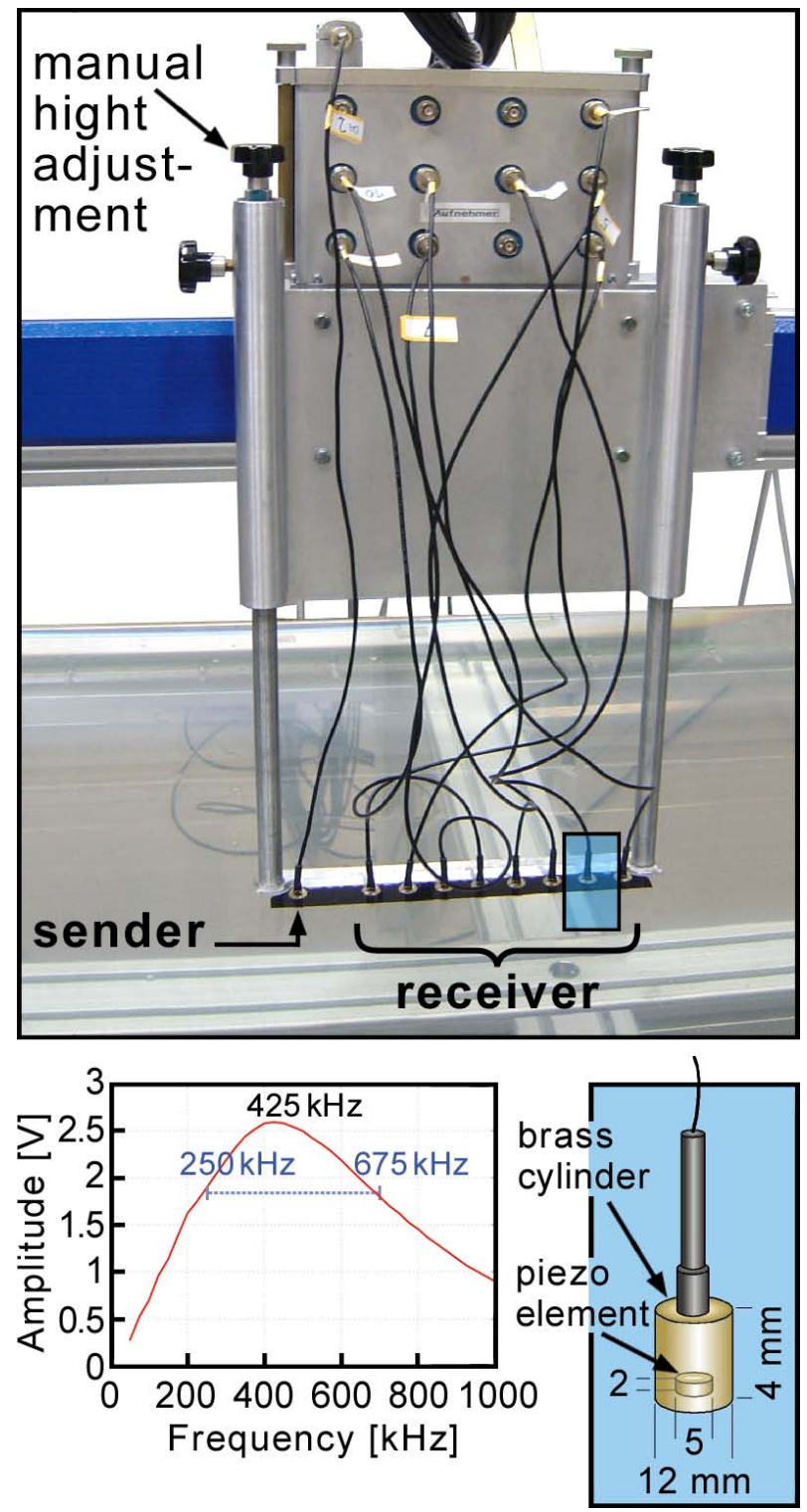

Fig. 3. Transducer array (top) and technical characteristics of the piezoelectric elements used (bottom).

\subsection{Positioning system}

Two step motors move the sensors along the horizontal axes (Fig. 1). They can move any given source and receiver geometry horizontally within the tank, so that seismic profiles can be recorded at any position over the model, resembling scaled 2-D marine survey geometries.

The maximum traverse path is $1 \mathrm{~m}$ depending on sensor configuration. With an accuracy of $0.12 \mathrm{~mm} / \mathrm{motor}$ step, it is possible to move an array, to any defined position, with sufficient precision (Table 1).

\subsection{Transducers}

Piezoelectric transducers that are lowered into the tank are used as ultrasound source and receivers (Fig. 3). They can be assembled with a rack design of any geometry. So far, twelve receivers and one emitter (custom-made product) with piezoelectric converters are in use.

Coated by a damped brass cylinder of $12 \mathrm{~mm}$ diameter and $20 \mathrm{~mm}$ height, the leadmethaniobate piezoelectric element contained is $2 \mathrm{~mm}$ high and $5 \mathrm{~mm}$ in diameter. It is glued to a thin brass plate, so that internal reflections are negligible. The performance of the piezoelectric transducers has been extensively tested (see Buddensiek et al., 2009), showing maximum sensitivity at $425 \mathrm{kHz}$ with half-power bandwidth between $250-675 \mathrm{kHz}$ (see Fig. 3, Table 1). After analysing effective diameter of the transducers, directionality, changes in waveform, and frequency sensitivity, Buddensiek et al. (2009) recommend to use signal frequencies of 350 to $550 \mathrm{kHz}$, with incidence angles below $35^{\circ}$ and source receiver-offsets less than $14 \mathrm{~cm}$ in order to exploit the piezoelectric transducers in an optimal way, even though this defines a smaller maximum source-receiver offset than modern marine multichannel seismic surveys would require for direct comparison (e.g. Long, 2010). The experimental setup here finally allows the imaging of structures as small as 2.0 $1.5 \mathrm{~mm}$ size.

\section{Test experiments}

The maximum source frequency of $1 \mathrm{MHz}$ allows for a very high resolution in the $\mathrm{mm}$ range, depending on the velocity of the material. However, if the resolution is close to the grain size, the grains cause scattering effects and attenuation, so that the $\mathrm{S} / \mathrm{N}$ ratio is impaired. With one source and 12 simultaneously recording receivers we have, therefore, performed test and calibration experiments to decide about model preparation and to work out sufficient imaging quality. The acquisition geometry is based on 18 to $150 \mathrm{~mm}$ shot-receiver spacing, $12 \mathrm{~mm}$ receiver spacing, $3 \mathrm{~mm}$ shot spacing and $100 \mathrm{~mm}$ water depth. This design is adapted to resolve faults and other structures of a few mm width, as they are to be expected in sandbox models. The source specifications and processing parameters varied and are given accordingly in the following subchapters.

\subsection{Principle geometries}

In order to determine the possibilities and limits of our apparatus to image geological structures, the first 2-D experiments are kept very simple. Two-layer models with layers composed of different materials (water-saturated sand of different grain sizes and resin-saturated sand) or different material densities are acquired for testing also variable layer thicknesses and different source frequencies (Fig. 4). For all experiments presented here, a sinusoid source wavelet of four 


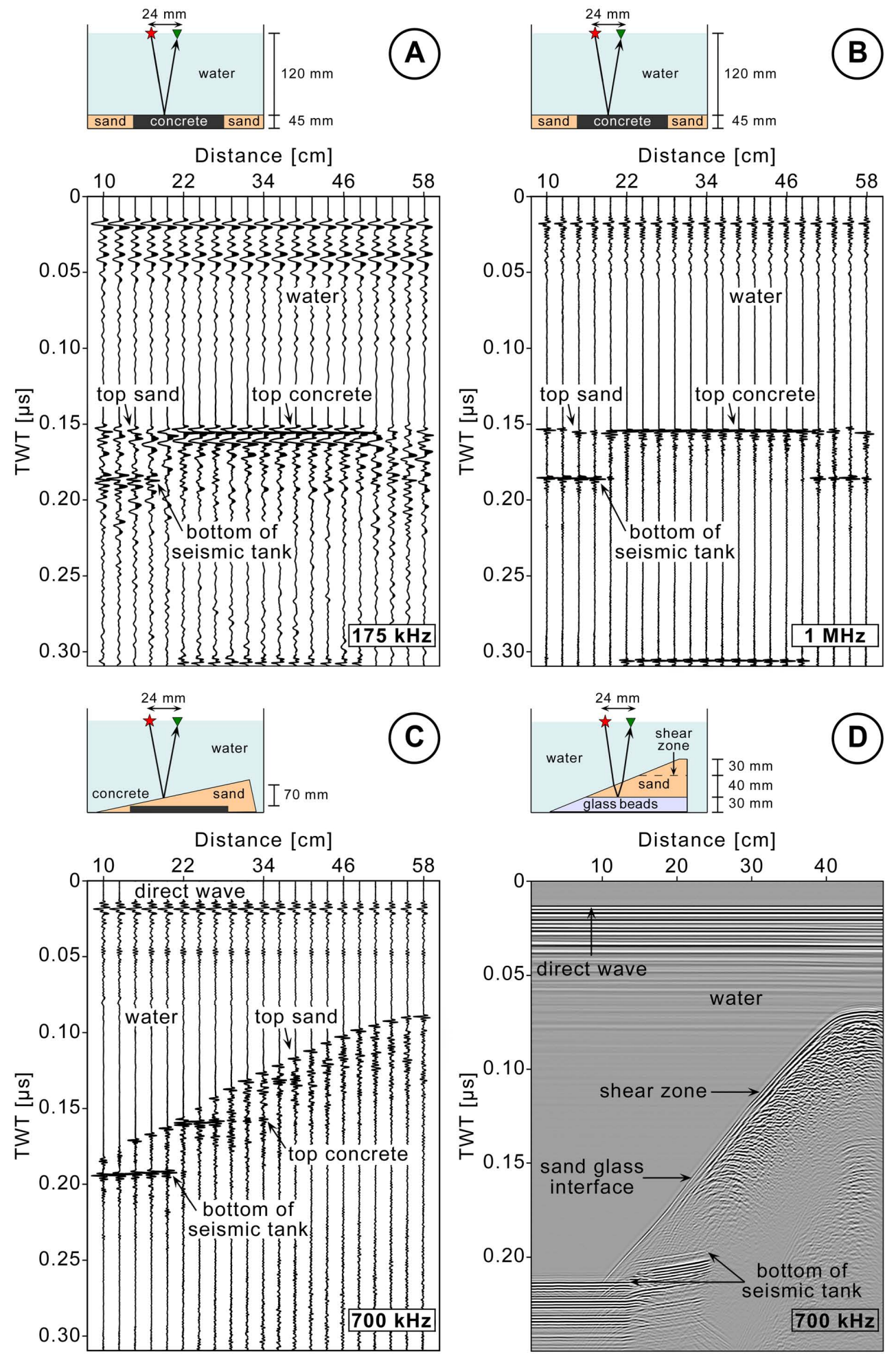

Fig. 4. Principle experiment geometries and resulting common-offset gathers from different test series acquired with the laboratory seismic system. (A, B) Flat reflector experiments testing different source frequencies; (C, D) wedge experiments with different layer materials for attenuation and scattering analyses (note the larger vertical scale in (D)). 
periods tapered by a squared cosine, 16 -fold vertical stacking, and a sampling rate of $20 \mathrm{MHz}$ were applied.

A first experiment series acquired data across a flat lying, $4.5 \mathrm{~cm}$ thick concrete body embedded in sand (Fig. 4a, b). Here, the source frequency varied systematically between $100 \mathrm{kHz}$ and $1 \mathrm{MHz}$. The results show that resolution and attenuation are much higher using a $1 \mathrm{MHz}$ source frequency than is observed in the $175 \mathrm{kHz}$ experiment. Sufficient energy passes through the sand to be reflected at the bottom of the seismic tank, whereas no bottom reflection can be seen underneath the concrete-water interface due to the higher attenuation for high frequencies (Fig. 4a, b).

The next experiments acquired data across a wedgeshaped body, consisting of either concrete in sand (Fig. 4c) or a layer of glass-bead beneath a sand wedge (Fig. 4d). For both experiments the source frequency was $700 \mathrm{kHz}$. Reflections from the top of the concrete can be seen for up to $4.5 \mathrm{~cm}$ of sand layer thickness, when attenuation becomes too high for the high-frequency P-waves (Fig. 4c). For the glass-bead setup, the resulting seismogram shows significant noise due to scattering, so that no clear reflection of the sandglass-bead interface is visible. However, the glass bead layer contains less scattering noise than the sand layer due to the longer wavelength of the P-wave signal. Despite this, the artificially introduced shear zone in the top third of the wedge can be more clearly resolved (Fig. 4d).

Additionally, first parameter tests show that models with sand grains $<0.4 \mathrm{~mm}$ and a source frequency of $250 \mathrm{kHz}$ produce reasonably high data quality. Furthermore, reflections of an interface between uncompacted sand with grain size $<0.6 \mathrm{~mm}$ and denser, compacted sand (grain size $<0.4 \mathrm{~mm}$ ) can be picked in the seismic sections using a source frequency of $350 \mathrm{kHz}$.

\subsection{Interface preparation}

We performed a second series of experiments in order to determine which model setup could create the strongest interface reflections. The interface model is a two-layer model that consists of four different granular materials, combined with four different procedures of interface preparation, so that 16 fields of interface variations can be analysed (Fig. 5). Layer thickness is constant at $2 \mathrm{~cm}$, and the fields are $10 \mathrm{~cm} \times 10 \mathrm{~cm}$ in size. Interface preparation either consisted of flat grading by soft stamping, of sprinkling with glass powder (40 to $70 \mu \mathrm{m}$ diameter), of applying both, or none of them (for more detail see Buddensiek, 2009). Four profile locations cover the four different material interfaces, while the preparation types are surveyed inline (Fig. 5).

After a saturation time of three days, the seismic profiles were surveyed. For all sections presented here, a sinusoid source wavelet of four periods tapered by a squared cosine, 16-fold vertical stacking, and a sampling rate of $20 \mathrm{MHz}$ have been applied. For seismic processing we only used the $450 \mathrm{kHz}$ source frequency shots recorded at $18 \mathrm{~mm}$ off-

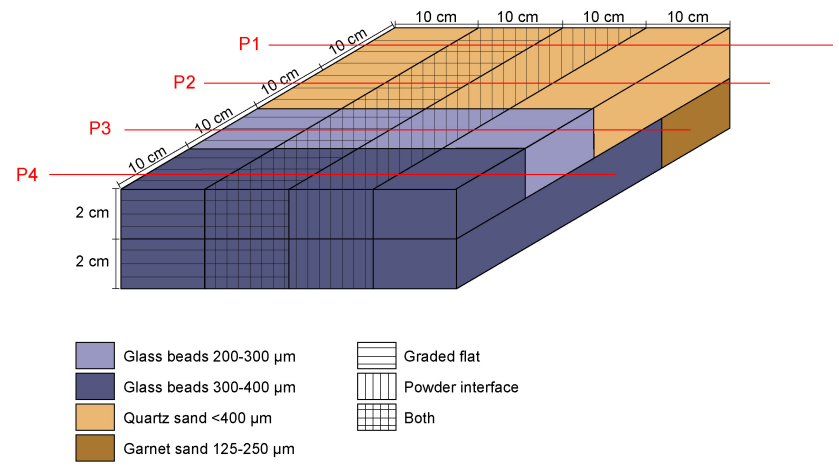

Fig. 5. Setup of the interface model to test seismic imaging properties of selected granular materials and of differently prepared interfaces. The lines labelled P1-P4 mark the locations of the seismic sections shown in Fig. 6.

set, the nearest shot-receiver distance. Due to data acquisition very near to the model surface, only this trace provided enough sensitivity and a clear signal. Therefore, processing was kept simple by filtering only with an automatic gain control (AGC) of $0.04 \mu \mathrm{s}$ window size.

From top to bottom, Fig. 6 reveals very different imaging results in the 16 fields of analysis (cf. Fig. 5). In all profiles both the surface of the model as well as the plexiglass bottom are easily identified as model boundaries. The ringing below the plexiglass reflections is dominant in profiles $\mathrm{P} 1$ and $\mathrm{P} 2$, while attenuation and scattering are higher in profiles $\mathrm{P} 3$ and P4 (Fig. 6). This directly relates with the material properties of either glass beads or sand, and with very high internal noise encountered in quartz and garnet sand, thereby hampering almost any reflection identification on profiles $\mathrm{P} 3$ and P4. Even the plexiglass bottom almost vanishes against the strongly pronounced multiple.

Glass beads of the same size constitute the layers of profile P1 (Fig. 6, P1). The interface, expected at ca. 0.09-0.1 $\mu$ s, is faintly imaged where it had been prepared by powdering and grading plus powdering. The other panels, with no preparation or grading only, do not reveal clear reflectors. This observation also holds for profile $\mathrm{P} 2$, where reflections of the interface are strongest, because here glass beads of different size represent different layer properties. The upper layer shows only little noise, whereas the lower layer in profile P2 is more obscured, presumably by the diffractions generated at the interface that also affect the plexiglass signal (Fig. 6, $\mathrm{P} 2$ ). Profiles P3 and P4 yield a completely incoherent signal quality and, if any, only strongly discontinuous reflectivity, which could be expected for sands. Here, only internal scattering and noise occur, and the upper quartz sand layer already consumes the entire wave energy. Solely the water bottom multiple remains visible (Fig. 6, P3 and P4). Slope variations at the left side of the sections result from a collapse of the model boundary during the saturation phase prior to the seismic experiment. 


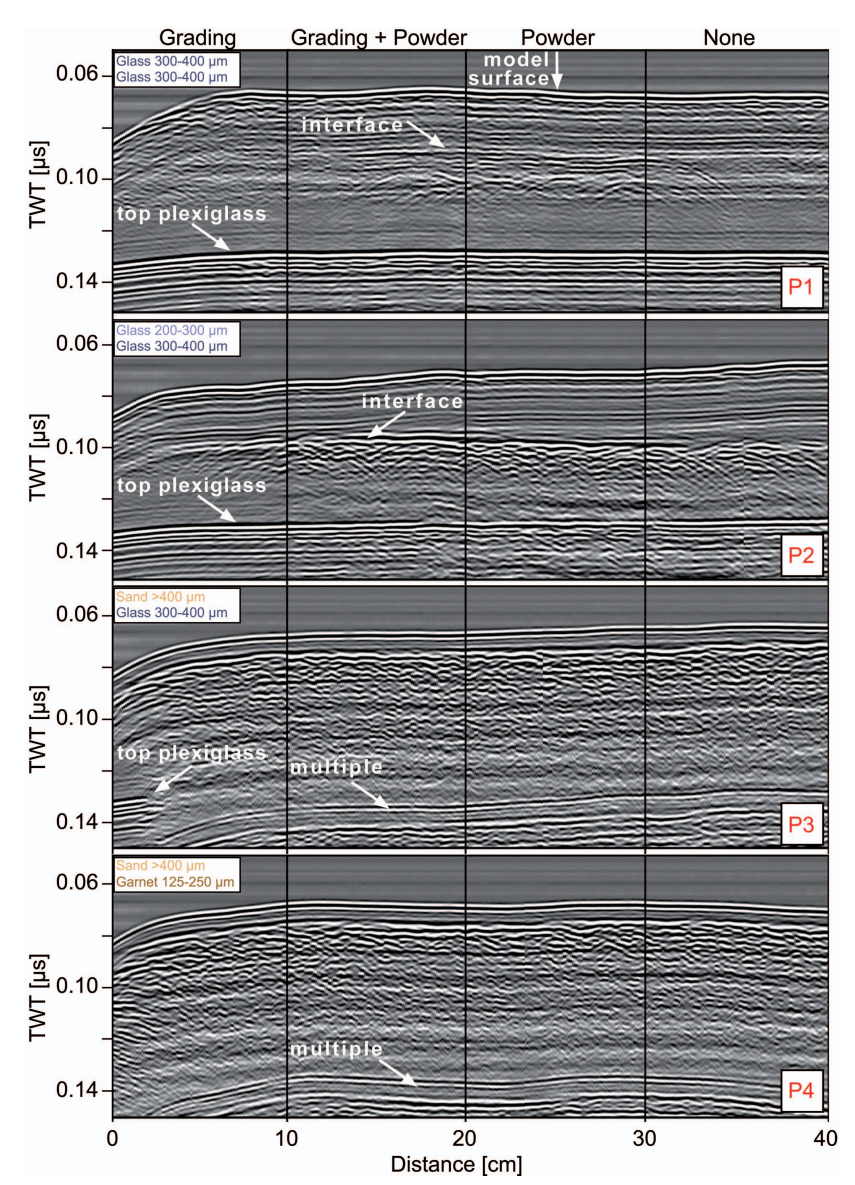

Fig. 6. Reflection seismic sections across the interface model located at lines P1-P4 given in Fig. 5. The interface is best imaged when it is prepared by grading and powder as well as between wellrounded and well-sorted glass beads (P1, P2).

In summary, the interface model experiment series suggests that grading flat plus powdering is the best suited procedure for interface preparation, which seems to be more important for good imaging than the material itself. Furthermore, the use of well-rounded and well-sorted material (glass beads) is recommended. Three days of saturation time should be sufficient in most cases.

\section{Reflection seismic imaging}

This advanced experiment series finally aimed at imaging different structural features by reflection seismic profiling across a 3-D model. The channel model has two layers of glass beads of different size, with their interface being prepared by flattening and powdering (Fig. 7). This procedure and the material used were chosen accordingly to the results gained from the second experiment series (see above). The channel model is $5 \mathrm{~cm}$ thick. It contains three distributed, $1 \mathrm{~cm}$ deep channels, and a $30^{\circ}$ dipping shear band created by pulling a string through the model after saturation of three
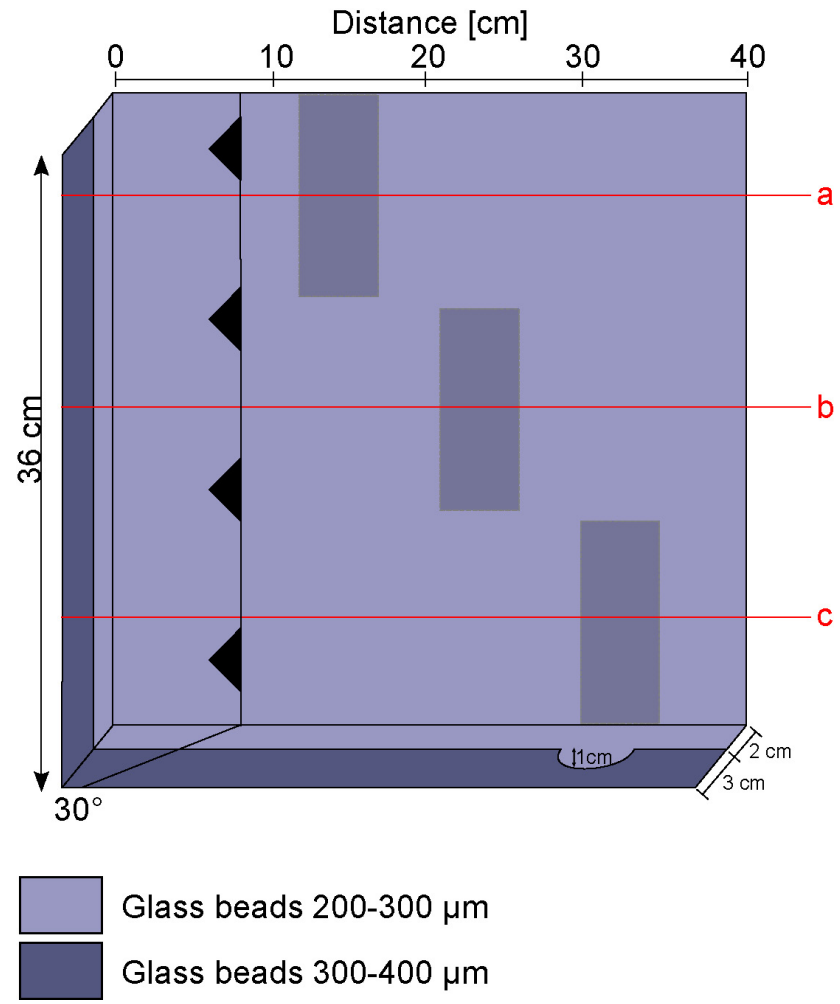

Fig. 7. Setup of the channel model consisting of two glass-bead layers. While a shear zone of $30^{\circ}$ dip angle is prepared close to the left side of the analogue model, a channel structure is distributed over three positions in the model. Lines a-c mark locations of the seismic sections shown in Fig. 9.

days (cf. Buddensiek, 2009 for experimental details). The resulting dilation and decompaction may be considered equivalent to that known to occur in natural fault zones and their process zone. Three seismic profiles were shot across the different channel locations and the shear zone (Fig. 7).

The acquisition geometry with 12 receivers was kept to $18-150 \mathrm{~mm}$ shot-receiver spacing, $3 \mathrm{~mm}$ shot spacing and $100 \mathrm{~mm}$ water depth. The source frequency was varied from 300 to $650 \mathrm{kHz}$, with $50 \mathrm{kHz}$ intervals for individual frequency stacks of 256 vertical fold. For signal recording a sampling interval of $0.05 \mu$ s was chosen. The reflection seismic processing sequence comprised frequency stacking, spherical gain application, bandpass filtering $(75,125,750$, $800 \mathrm{kHz})$, normal move-out (NMO) correction $\left(1485 \mathrm{~m} \mathrm{~s}^{-1}\right.$ constant velocity), stacking and time migration ( $t-k$ domain). While the raw shot data have a limited vertical resolution between $1.2-1.7 \mu$ s (Fig. 8a), the frequency stacking improves the resolution during processing so that the interface reflector can be clearly identified (Fig. 8b).

With good quality, the three reflection seismic profiles, across the channel model, all image the predefined structures (Fig. 9, profiles a to c). The common-offset gathers reveal the preprocessed data quality, where diffraction hyperbolas 

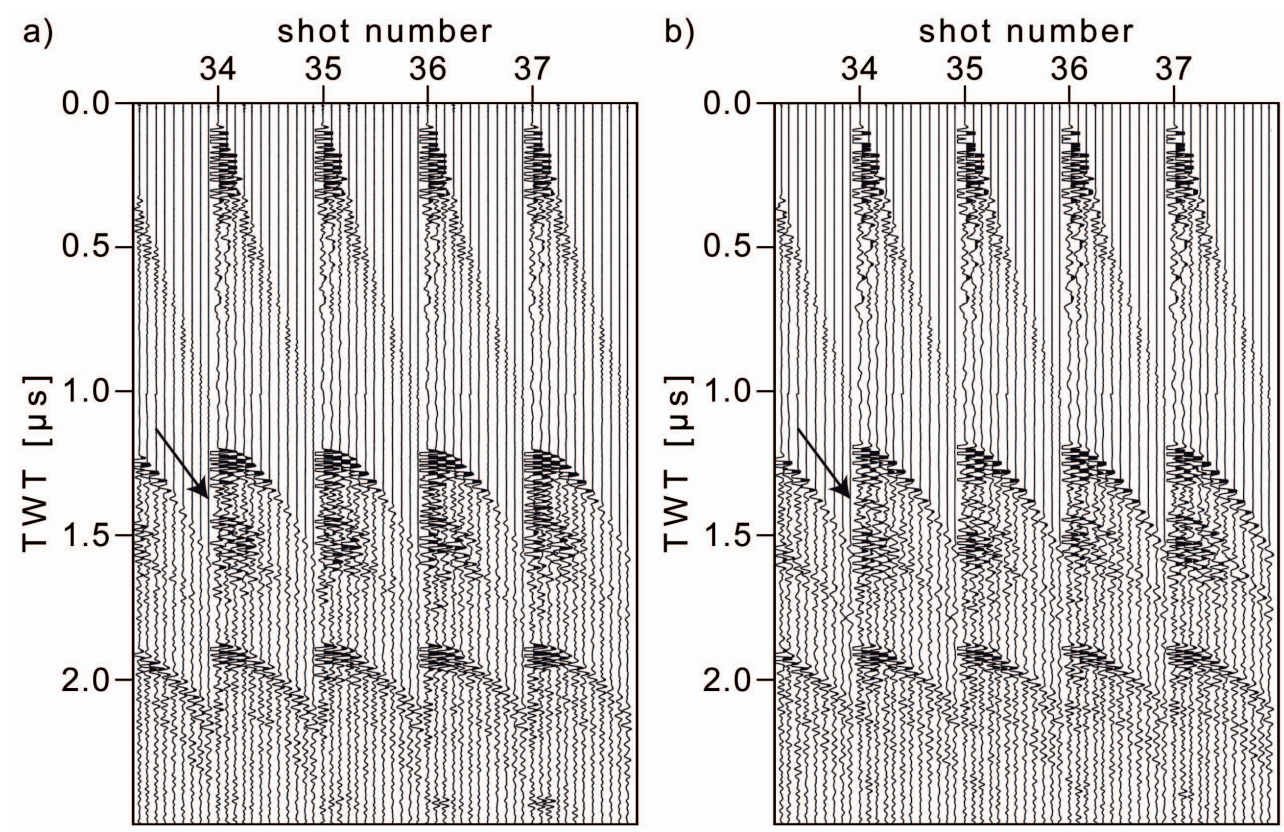

Fig. 8. Shot gathers of the channel model from the $450 \mathrm{kHz}$ recording, (a) after spherical gain, and (b) after frequency stack followed by spherical gain. Here, the interface reflection at ca. $1.35 \mu$ s is much better resolved (see arrows).

occur at the surface outcrop of the shear band, thereby blurring the layer below (e.g. Fig. 9, left, profile a: $8-12 \mathrm{~cm}$ distance, $0.12-0.14 \mu \mathrm{s}$ ). As one would expect, largest diffractions are encountered from the flanks of the channel structure (e.g. Fig. 9, left, profile b: $25-30 \mathrm{~cm}$ distance, $0.15 \mu \mathrm{s}$ ), but also a number of small amplitude diffractions were generated at the layer interface (Fig. 9 left, all profiles: below $0.15 \mu \mathrm{s}$ ). Thus, the lower layer of the model appears noisier than the upper one. The model surface runs continuously across the sections, while the plexiglass bottom reveals a different amplitude behaviour in spite of a continuous reflection. It has a strong reflection where the interface is weak, and vice versa.

With respect to the quality of the source wavelet, especially the ringing that is still contained in the data and the duration of the source wavelet must be considered. These two aspects arose from the technical limitations. Firstly, the entire surface of source and receiver contributes to the recorded waveform, so it is not equal to the digitally produced waveform. Secondly, the piezo-crystal has a tendency to ring after excitation, in particular in its eigenfrequency of $110 \mathrm{kHz}$ and multiples. To dampen this ringing as much as possible, the sensor cylinders are filled with a damping material. The remaining ringing cannot be reduced without decreasing the output energy and thus penetration depth. Internal interactions between the crystal, the damping, the cylinder walls, the brass bottom, and the glue are considered negligible because of their small size compared to the wavelength (cf., Buddensiek et al., 2009). To improve the signal as much as possible (large amplitude, less ringing, relatively wide frequency spectrum), we tested a number of source wavelet shapes, fre- quencies, and frequency stacks. We found that the preferred source frequency of $250-675 \mathrm{kHz}$ generates a signal such that over an offset (source to reflection point, not receiver) of $120 \mathrm{~mm}$ only the first two phases interfere constructively, so NMO-stacking reduces the ringing to some degree. In the zero-offset profiles, the ringing is not reduced at all (cf., discussion in Buddensiek, 2009).The migrated sections disclose the advantage of the multifold acquisition after NMO stacking. The diffractions described above are collapsed and the channel geometries are well defined (Fig. 9 right, all profiles: below $0.14 \mu \mathrm{s}$ ). Even the footprint of the shear band on the interfaces is much better revealed from the surface down to at least the interface (Fig. 9 right, all profiles: 0.12 to $0.14 \mu$ s). The shear zone images by the interuption of the very strong bounding reflectors in the upper part. This effect is comparable to observations in the field across different scales (e.g. Krawczyk et al., 2002, 2006 and references therein). In addition, the shear zone can be further traced as smeared type of reflection zone down to the interface (best pronounced in Fig. 9b, right panel). Between the interface and the plexiglass bottom, however, the shear zone signal diminishes. This may be caused by the lower impedance contrast across the shear band if compared to the energy reflected at the layer interface.

After time migration, the measured travel-time values and the known thicknesses from model preparation allow to check the consistency of our measurements. Picking the twoway travel times from model surface, interface and plexiglass bottom, these layers are found on average at $0.12 \mu \mathrm{s}$, $0.144 \mu$ s and $0.187 \mu$ s. Calculating with a velocity value of 

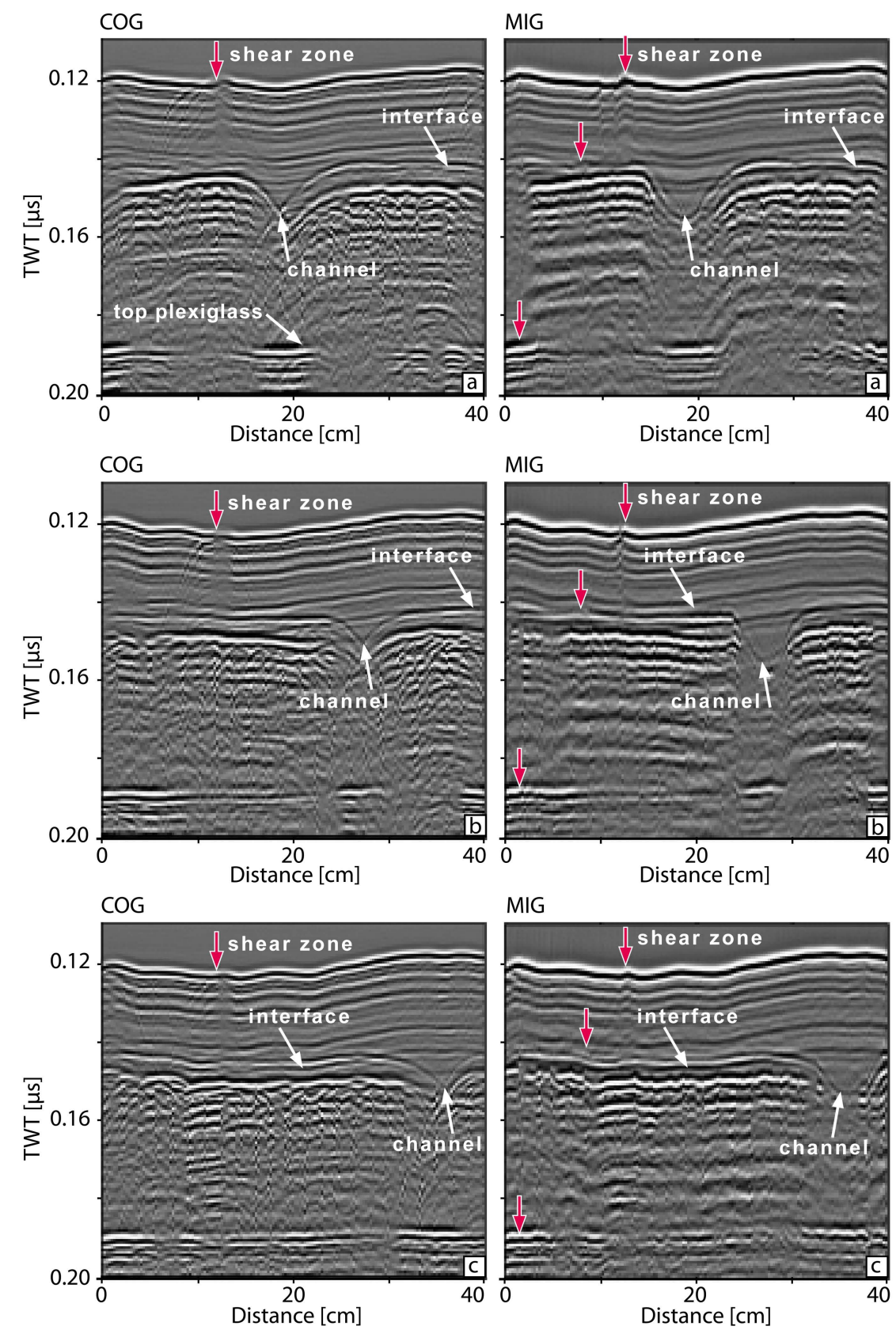

Fig. 9. Constant-offset gathers (COG; left) and time-migrated sections (MIG, right) image the channel model at three different profile positions across the analogue model (cf. Fig. 7, profiles a-c; vertical exaggeration is ca. 6). The distance between shear zones and channel structures varies, but in all sections these can be clearly imaged separately. The subtle traces of the shear zone are indicated by red arrows.

$1485 \mathrm{~m} \mathrm{~s}^{-1}$ in the water column, the depth between transducers and model surface amounts to $9 \mathrm{~cm}$, which is exactly the geometry used. The thickness of the upper model layer is $2 \mathrm{~cm}$ plus $1 \mathrm{~cm}$ where a channel is met. Assuming a velocity of $1600 \mathrm{~m} \mathrm{~s}^{-1}$, the two-way travel times of $0.024 \mu \mathrm{s}$ and $0.012 \mu$ s fit very well. Inconsistencies in the thickness of the bottom layer may reach a few $\mathrm{mm}$, if both model layers have the same velocity, which may be caused by imprecise sieving during model preparation or by incomplete velocities during migration.

Hence, the channel model has proven that variable layer thicknesses as well as shear bands are detected by seismic imaging of analogue models. Even though the fault is most clearly visible in the upper part of the top layer, it can also be imaged after stacking and migration in the deeper parts of the glass-bead layers. With our hardware setup the penetration depth of this experiment is approximately $5 \mathrm{~cm}$. 


\section{Discussion}

The seismic sections of the interface model (Fig. 6) and channel model (Fig. 9) clearly showed that seismic surveys across glass-bead models are more likely to produce clear reflections of interfaces, if these are carefully prepared and an array-technique is applied. The downside of models containing interfaces is that a substantial part of the energy is reflected. Thus, the energy output of our source achieves a penetration depth of approximately $5 \mathrm{~cm}$, which could not be improved by additional vertical stacking. None of the experiments was able to image an interface within sand. Since, in nature, most structural geologic information is achieved by imaging interfaces, and faults are usually inferred from horizon offsets, future experimental setups and experiments will have to focus on the interface preparation aspect for comparability with geometries observed in nature. Moreover, the current restriction in depth penetration will require the development of stronger sources while maintaining the frequency spectrum. Because of the required resolution of 1 to $3 \mathrm{~mm}$, the source frequency cannot be lowered to achieve a higher penetration. However, if it is desired to perform multipleoffset processing, the source should, at the same time, emit a broad beam in the same frequency range.

Scaling the laboratory experiments to field surveying, modern marine seismic surveys would imply the use of wider incidence angles for larger source-receiver offsets (see sect. 2.4) as well as modified acquisition geometries. Here, we introduced acquisition parameters adapted to the technical facilities available at the time. Because of the narrow angle reception, we chose relatively high water depths to ensure that any reflection would be received at the furthest offset. For future experiments, the receiver spacing should be reduced, the shot-receiver spacing should start at lower values to account for small offsets, and the shot spacing could be denser. Nonetheless, the major aim of our study, proving the feasibility of such kind of laboratory seismics for sandbox experiments, is met here.

In the migrated seismic sections (Fig. 9), the artificially introduced shear zone is not imaged as a reflector itself but can be seen in a very small offset at the interfaces (like in field surveys). This shear band can be traced well down to $2.5 \mathrm{~cm}$ depth within sand, while the seismic expression of the shear band in glass beads is much smaller (Fig. 9, marked by arrows). The difference between both sections lies mostly in the material. Sand has a rougher surface, i.e. higher friction. Therefore, the grains are prone to stay in their displaced position after the string was pulled through. The smooth glass beads are more likely to fall back into place, so that the decompaction is not a permanent expression. In this case, not even less attenuation or a stronger source would enable us to resolve the shear zone. Nevertheless, considering the test experiments imaging artificially induced shear zones as zones of disturbance here, seismic imaging is expected to locate more clearly zones of decompaction, and thus tectonic shear zones, within models that have undergone deformation. Ring shear testing of granular materials undergoing deformation first observe compaction before localized decompaction occurs along the zone of failure (Lohrmann et al., 2003). Therefore, the density contrast of shear zones versus undeformed material is even higher, and should be resolved even better in actively deforming models than in this simple simulation. If interfaces are present, the faults and their offset can be seismically imaged in glass-bead models down to $2 \mathrm{~cm}$. If additional interfaces are present below the depth resolution for faults, the faults and their offset can be inferred from horizon offsets. In sand models, only the faults are well-resolved, but not the interfaces that are needed to infer an associated offset.

The seismic sections of the interface model (Fig. 6) show that the image quality over the glass-bead profiles (P1 and $\mathrm{P} 2$ ) is much better than over the sand profiles (P3 and P4). A bigger 3-D model composed of sand would contain even more internal noise and attenuation. Since it is difficult to saturate sand models due to the rough surface of the grains, the imaging quality is variable from model to model and within one model. This result shows that sand, or any other granular material with a rough surface, is not suitable for seismic imaging with the preparation and saturation method that we use.

The discussion of the grain surface texture indicates a conflict of interest: A rough surface of the grains, i.e. higher friction, (1) creates proper shear bands that can be resolved in the seismic data, but (2) inhibits the saturation, which causes attenuation and noise. To avoid this conflict, the saturation needs to be improved. We used hot water of ca. $50^{\circ} \mathrm{C}$ to saturate, and waited for three days until the signal did not undergo further change. Further saturation can be achieved by a vacuum chamber, vibrations, a longer saturation time, and/or saturation with near boiling hot water. A vacuum chamber is not available for a setup of this size and vibration cannot be used, since it disturbs the packing, particularly at an interface. If the saturation time is supposed to take more than four days, we recommend using distilled water because of algae and other organic growth. In addition, the use of a low viscosity fluid with lower surface tension and wetting angle in contact to glass beads or sand may help to improve imaging quality.

Despite the limitations encountered during our experiments, recording multiple-offset traces and reflection processing was able to improve the image quality, also in comparison to Sherlock (1999) and Sherlock and Evans (2001), whose seismic modelling of granular material based on zerooffset data suffered from high attenuation and especially scattering. These imaging capabilities also supplement the vibrometry method of Bodet et al. (2010) that allows the derivation of elastic properties only. Since we are now able to resolve the interfaces within glass-bead models, we can interpret faults in laboratory data like in field data. 


\section{Conclusions and outlook}

We have designed and developed a new mini-seismic facility for laboratory use. It consists of a seismic tank, a PC control unit, a positioning system and includes piezoelectric transducers. First experiments with this setup have shown that ultrasonic seismic experiments are able to resolve structures within simple models of saturated porous media. The analysis of the seismic response as a function of layer thickness, material density contrast, and source frequency supports the design of future sandbox models to resolve specific structures systematically. Here, we suggest to use well-sorted and wellrounded grains with little surface roughness (glass beads), and to prepare the interfaces by grading and powdering to achieve a good imaging quality.

The acquisition and processing scheme that takes advantage of the redundant information provided by an array of receivers has proven successful here for more geological models. With the array-technique of piezoelectric transducers introduced here, we found the best compromise between wide beam and high energy output, the technique being applicable up to $14 \mathrm{~cm}$ offset with a consistent waveform. This enables imaging of structures as small as $2.0-1.5 \mathrm{~mm}$ size.

Seismic reflection imaging of different saturated analogue models detects layering and shear bands. Fault images can be resolved also in glass-bead layering with increasing amplitude to larger depth. The multiple-offset surveying improves the data quality with respect to the $\mathrm{S} / \mathrm{N}$ ratio and allows for further processing steps, such that a depth penetration in glass-bead layers of up to $5 \mathrm{~cm}$ is reached.

With respect to model and hardware setup, further developments should encompass the improvement of model saturation, the use of viscous material to simulate mantle material or salt domes, and the design of smaller sources with higher energy output and perfect signal control. Especially for more complex models, the image clarity and penetration depth need to be improved (setup of thin layer models) to study actively evolving models with this method. In the future, differences in wave propagation between field experiments and our laboratory system must be investigated to be able to compare both data records. At this point, the advantage of laboratory studies, which is the a priori knowledge of media characteristics, was not considered yet and should be evaluated further, e.g. to calibrate interpretations.

Beyond these specifically seismic techniques, the incorporation of fluid pressures and permeability changes between different layers would greatly enhance the potential to simulate critical taper models. However, the experiments show that multiple-offset seismic imaging of shallow sandbox models, that are structurally evolving, is generally feasible.
Acknowledgements. We thank Günter Tauscher and Thomas Ziegenhagen for their technical assistance in the laboratory, GMuG $\mathrm{mbH}$, Bad Nauheim for technical support and sharing the codes, as well as Don Sherlock and Silvan Hoth for discussion. Reviews from Raphael Bartolomé, Marc-André Gutscher and Donatienne Leparoux are gratefully acknowledged. This study was funded by the Helmholtz Centre Potsdam, GFZ German Research Centre for Geosciences.

Edited by: V. Sallares

\section{References}

Adam, J., Urai, J. L., Wieneke, B., Oncken, O., Pfeiffer, K., Kukowski, N., Lohrmann, J., Hoth, S., van der Zee, W. and Schmatz, J.: Shear localisation and strain distribution during tectonic faulting - new insights from granular-flow experiments and high resolution optical image correlation techniques, J. Struct. Geol.,, 27, 283-301, 2005.

Adam, J., Schreurs, G., Klinkmüller, M., and Wieneke, S.: 2-D/3-D Strain localisation and fault simulation in analogue experiments: insights from X-ray computed tomography and tomographic image correlation, Bolletino di Geofisica, 49, 21-22, 2008.

Baldassarre, A., DeLucia, M., Nesi, P., and Rossi, F.: A VisionBased Particle Tracking Velocimetry, Real-Time Imaging 7, 145-158, 2001.

Bodet, L., Jacob, X., Tournat, V., Mourgues, R., and Gusev, V.: Elasticity profile of an unconsolidated granular medium inferred from guided waves: Toward acoustic monitoring of analogue models, Tectonophysics, 496, 99-104, doi:10.1016/j.tecto.2010.10.004, 2010.

Boutelier, D. and Oncken, O.: 3-D thermo-mechanical laboratory modeling of plate-tectonics: modeling scheme, technique and first experiments, Solid Earth, 2, 35-51, doi:10.5194/se-2-352011, 2011.

Bretaudeau, F., Leparoux, D., Durand, O. and Abraham, O.: Smallscale modeling of onshore seismic experiment: A tool to validate numerical modeling and seismic imaging methods, Geophysics, 76, T101-T112, doi:10.1190/GEO2010-0339.1, 2011.

Buddensiek, M.-L.: Seismic imaging of sandbox models, PhDThesis, FU Berlin, http: http://www.diss.fu-berlin.de/diss/ receive/FUDISS_thesis_000000009439, last access: February 2013, 2009.

Buddensiek, M.-L., Krawczyk, C. M., Kukowski, N., and Oncken, O.: Performance of piezo-crystal transducers with respect to amplitudes and waveform in laboratory seismic application, Geophysics, 74, T33-T45, 2009.

Colletta, B., Letouzey, J., Pinedo, R., Ballard, J. F., and Bale, P.: Computerized X-ray tomography analysis of sandbox models: examples from thin skinned thrust systems, Geology, 19, 10631067, 1991.

Davis, D., Suppe, J., and Dahlen, F. A.: Mechanics of fold-andthrust belts and accretionary wedges, J. Geophys. Res., 88, 1153$1172,1983$.

Gartrell, A., Hudson, C., and Evans, B.: The influence of basement faults during extension and oblique inversion of the Makassar Straits rift system: Insights from analog models, AAPG Bull., 89, 495-506, doi:10.1306/12010404018, 2005. 
Graveleau, F. and Dominguez, S.: Analogue modelling of the interaction between tectonics, erosion and sedimentation in foreland thrust belts, C. R. Geosci., 340, 324-333, 2008.

Graveleau, F., Malavieille, J., and Dominguez, S.: Experimental modelling of orogenic wedges: A review, Tectonophysics, 538540, 1-66, 2012.

Hampel, A., Adam, J., and Kukowski, N.: Response of the tectonically erosive South Peruvian forearc to subduction of the Nazca ridge: analysis of 3-D analogue experiments, Tectonics, 23, TC5003, doi:10.1029/2003TC001585, 2004.

Holland, M., van Gent, H., Bazalgette, L., Yassir, N., Hoogerduijn Strating, E. H., and Urai, J. L.: Evolution of dilatant fracture networks in a normal fault - Evidence from 4D model experiments, Earth Planet. Sci. Lett., 304, 399-406, doi:10.1016/j.epsl.2011.02.017, 2011.

Hoth, S., Hoffmann-Rothe, A., and Kukowski, N.: Frontal accretion: An internal clock for bivergent wedge deformation and surface uplift, J. Geophys. Res., 112, B06408, doi:10.1029/2006JB004357, 2007.

Hoth, S., Kukowski, N., and Oncken, O.: Distant effects in bivergent orogenic belts - How retro-wedge erosion triggers resource formation in pro-foreland basins, Earth Planet. Sci. Lett., 273, 28-37, doi:10.1016/j.eps1.2008.05.033, 2008.

Hubbert, M. K.: Theory of scale models as applied to the study of geological structures, Geol. Soc. Am. Bull., 48, 1459-1520, 1937.

Jacob, X., Aleshin, V., Tournat, V., Leclaire, P., Lauriks, W., and Gusev, V. E.: Acoustic Probing of the Jamming Transition in an Unconsolidated Granular Medium, Phys. Rev. Lett., 100, 158003, doi:10.1103/PhysRevLett.100.158003, 2008.

Krantz, R. W.: Measurement of friction coefficients and cohesion for faulting and fault reactivation in laboratory models using sand and sand mixtures, Tectonophysics, 188, 203-207, 1991.

Krautkraemer, J. and Krautkraemer, H.: Werkstoffprüfung mit U1traschall, Springer Verlag, Berlin, 1986.

Krawczyk, C. M., Eilts, F., Lassen, A., and Thybo, H.: Seismic evidence of Caledonian deformed crust and uppermost mantle structures in the northern part of the Trans-European Suture Zone (TESZ), SW Baltic Sea, Tectonophysics 360, 215-244, 2002.
Krawczyk, C. M., Mechie, J., Lueth, S., Tasarova, Z., Wigger, P., Stiller, M., Brasse, H., Echtler, H. P., Araneda, M., and Bataille, K.: Geophysical Signatures and active tectonics at the SouthCentral Chilean margin, Front. Earth Sci., 1, 171-192, 2006.

Krawczyk, C. M., Buddensiek, M.-L., Philipp, J., Kukowski, N., and Oncken, O.: Midget seismic in sandbox models - hardware setup and first data generation, EAGE extended abstracts, E042, 5 pp., http://www.earthdoc.org/detail.php?pubid=6643, last access: February 2013, 2007.

Lohrmann, J., Kukowski, N., Adam, J., and Oncken, O.: The impact of analogue material properties on the geometry, kinematics, and dynamics of convergent sand wedges, J. Struct. Geol., 25, 16911711, 2003.

Long, A.: An overview of seismic azimuth for towed streamers, The Leading Edge, 29, 512-523, doi:10.1190/1.3422448, 2010.

Persson, K. S., Garcia-Castellanos, D., and Sokoutis, D.: River transport effects on compressional belts: First results from an integrated analogue-numerical model, J. Geophys. Res., 109, B01409, doi:10.1029/2002JB002274, 2004.

Reiter, K., Kukowski, N., and Ratschbacher, L.: The interaction of two indenters in analogue experiments and implications for curved fold-and-thrust belts, Earth Planet. Sci. Lett., 302, 132146, doi:10.1016/j.epsl.2010.12.002, 2011.

Rosenau, M., Nerlich, R., Brune, S., and Oncken, O.: Experimental insights into the scaling and variability of local tsunamis triggered by giant subduction megathrust earthquakes, J. Geophys. Res., 115, B09314, doi:10.1029/2009JB007100, 2010.

Schreurs, G., Hänni, R., Panien, M., and Vock, P.: Analysis of analogue models by helical X-ray computed tomography, Geol. Soc. Sp., 215, 213-223, 2003.

Sherlock, D. H.: Seismic imaging of sandbox models, $\mathrm{PhD}$ thesis, Curtin University, Perth, http://www.geophysics.curtin.edu. au/EGPPUBS/Docs/2000-000909-TPH.PDF, 1999.

Sherlock, D. H. and Evans, B. J.: The development of seismic reflection sandbox modelling, AAPG Bull., 85, 1645-1659, 2001.

Storti, F., Salvini, F., and McClay, K. R.: Synchronous and velocitypartitioned thrusting and thrust polarity reversal in experimentally produced, doubly-vergent thrust wedges - implications for natural orogens, Tectonics, 19, 378-396, 2000.

Wolf, H., König, D., and Triantafyllidis, T.: Experimental investigation of shear band patterns in granular material, J. Struct. Geol., 25, 1229-1240, 2003. 